\section{Safe Mechanical Preparation with Reciprocation Movement without Glide Path Creation: Result from a Pool of 673 Root Canals}

Evaldo Rodrigues ${ }^{1}$, Gustavo De-Deus², Erick Souza ${ }^{3}$, Emmanuel João Nogueira Leal Silva²

\begin{abstract}
The aim of the present study was to prospectively assess the frequency of teeth in which the Reciproc instruments were able to reach the full working length (WL). This case series study enrolled 277 consecutive teeth requiring primary endodontic treatment performed with the Reciproc system (VDW) without a previous glide path by 3 experienced endodontists. Instruments R25, R40 or R50 were selected, respectively, for narrow, medium and large canals, according to the preoperative radiographs, as per manufacturer recommendation. Canals were instrumented and classified as reaching the full WL (RFWL) and not reaching the full WL (NRFWL), according to the ability of the Reciproc instrument to reach without a glide path the full electronically determined WL. Finally, canals were filled using a single matched cone technique. Pearson's squared-chi test compared the frequency distributions of canals classified as RFWL and NRFWL. From a total pool of 673 root canals, Reciproc instruments reached the FWL in $96.28 \%$ of cases and 3 fractures occurred. For narrow canals the percentage of RFWL was $95.37 \%$ with 3 fractures. For medium and large canals, the R40 or R50 instruments reached the FWL in $98.51 \%$ and $97.62 \%$ of the cases respectively, with no fracture. Enlarging of root canals using the Reciproc instruments up to the FWL without a glide path is successful in a great percentage of cases. This case series suggests the possibility of using a single instrument to enlarge the root canal space of teeth by a simpler approach without an a priori glide path procedure.
\end{abstract}

\author{
${ }^{1}$ Department of Health, UEFS - \\ Universidade Estadual de Feira de \\ Santana, Feira de Santana, BA, Brazil \\ ${ }^{2}$ Department of Endodontics, Health \\ Sciences Center, UNIGRANRIO \\ - Universidade do Grande Rio, \\ Rio de Janeiro, RJ, Brazil \\ ${ }^{3}$ Department of Restorative Dentistry, \\ UFMA - Universidade Federal do \\ Maranhão, São Luis, MA, Brazil \\ Correspondence: Dr. Emmanuel \\ João Nogueira Leal Silva, Rua \\ Erotides de Oliveira 61/902 - 1caraí \\ 242.302-30 Niterói, RJ, Brasil. \\ Tel: +55-21-98357-5757. e mail \\ nogueiraemmanuel@hotmail.com
}

Key Words: Reciproc, instruments, glide path.

\section{Introduction}

From an endodontic standpoint, reciprocation can be defined as the sequence of repetitive and imbalanced backand-forth movements (1), which mechanically drive a given instrument. The recent introduction on the market of two reciprocation-based systems has raised new perspectives for the mechanical preparation of the root canal space. Reciprocating movement somehow mimics the manual movement (1) and to some extent, as recent studies showed, it outperformed conventional continuous rotary NiTi preparation (2-10). An interesting point addressed by one reciprocating system (Reciproc system, VDW, Munich, Germany) is the claim that it is able to prepare most root canals with no previous hand filing as, not rarely, the Reciproc file is able to swimmingly advance towards the apex (http://www.vdw-reciproc.de/en.html). This effortless and efficient inward advance toward the apex can be regarded as the result of the interplay between the instrument's cross-sectional design and flexibility, as well as the features of the reciprocating movement itself. In short, this means that the Reciproc system does not necessarily require the creation of a smooth and reproducible glide path for the majority of cases (http://www.vdw-reciproc. de/en.html). This is an innovative feature as creation of a glide path became a mandatory transoperative procedure due to its ability to minimize the risk of torsional fracture of NiTi rotary systems (11-13).

The possibility of using motor-driven NiTi instrument without the mandatory glide path requirement raises an interesting educational perspective inasmuch as the creation of an adequate, reproducible and smooth glide path is universally well-known as a technically demanding procedure, in which the difficulty degree is directly related to the curvature, atresia and length of the root canal and, not less important, to the experience of the operator $(14,15)$. Besides the potential no need for a glide path, the idea of using a single-file to safely create a final shape, which resembles a 25/.08 dimension, has a further educational appeal: the learning curve might be considerably reduced due to technique and endodontic armamentarium simplification.

A recent in vitro study demonstrated the possibility to enlarge straight and moderately curved mandibular molar root canals using a reciprocating system up to the working length without a glide path (7). The in vitro insight of this study points out to the clinical possibility of preparing a large number of ordinary root canals from molars without glide path; however, there is no clinical study demonstrating 
the possibility of safely using a reciprocating single-file up to the working length without a previous glide path. This sort of clinical evidence is powerful to enable professionals taking more predictable decisions.

The aim of this study was to assess the frequency of cases in which the Reciproc instruments were able to reach the full working length $(\mathrm{WL})$ without a glide path, when the selection of the Reciproc instruments is based on an assessment of the preoperative radiograph, according to the manufacturer's recommendation. The null hypothesis tested was that the Reciproc instruments in reciprocating motion would reach the FWL without a glide path in a lower frequency.

\section{Material and Methods}

\section{Ethical Issues, Subject Enrollment and Inclusion/ Exclusion Criteria}

Approval for the project was obtained from the University Research Board on Human Subjects (677.33), and informed consent was obtained from all participants. After approaching potentially appropriate patients, the practitioners carefully explained the purpose of the study and the patients were formally invited to participate. The clinical procedures were then explained, along with the risks and benefits related to the treatment. Patient's doubts were clarified when raised and written informed consent was obtained.

The main inclusion criterion was first or secondary maxillary molars routinely referred for primary endodontic treatment. The exclusion criteria were as follows: (i) retreatment cases, (ii) accesses through prosthetic crowns, (iii) case with incomplete root formation, (iv) patients younger than 16 years, and (vi) those who did not agree to participate in this study. However, no exclusion restriction was set regarding apical curvature, narrowness degree or partial radiographic visualization of root canal space, and teeth with former orthodontic treatment or dental traumatic injury history.

A pool of 277 teeth (172 molars, 79 premolars and 26 anterior) (151 maxillary and 126 mandibular) with root canal treatment indication was included in this report. Three experienced operators (ER, GD and ES), specialists in endodontics with more than 15 years of practice, performed all treatments in their private practice.

\section{Treatment Procedures}

After crown openings, the shaping procedure of the root canals was performed by a pecking motion using a dedicated reciprocating motor (VDW Silver) adjusted to the manufacturer's preset configuration "Reciproc ALL". The Reciproc instruments were chosen according to the manufacturer's recommendation, based on an adequate pre-operative radiograph, as previously described (16). Thus, if the canal was partially or completely invisible on the preoperative radiograph (Fig. 1A), the canal was considered as narrow and the Reciproc 25 was selected. In the other cases,
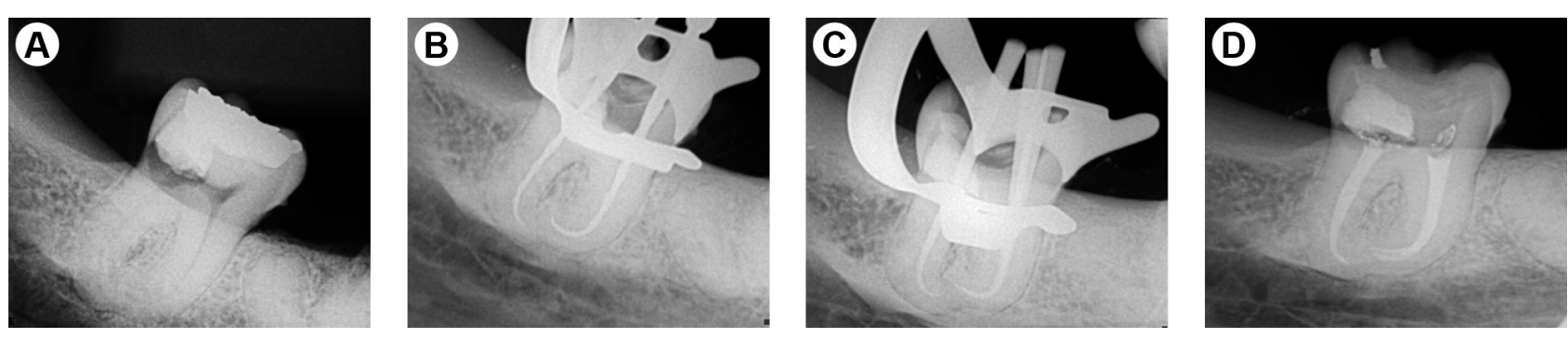

Figure 1. Case 1. A: Preoperative radiograph showing a partially invisible canal. The R25 file was indicated for this case; B: Transoperative radiograph showing the R25 at WL; C: Gutta-percha cones adapted to the WL; and D: Final radiograph.
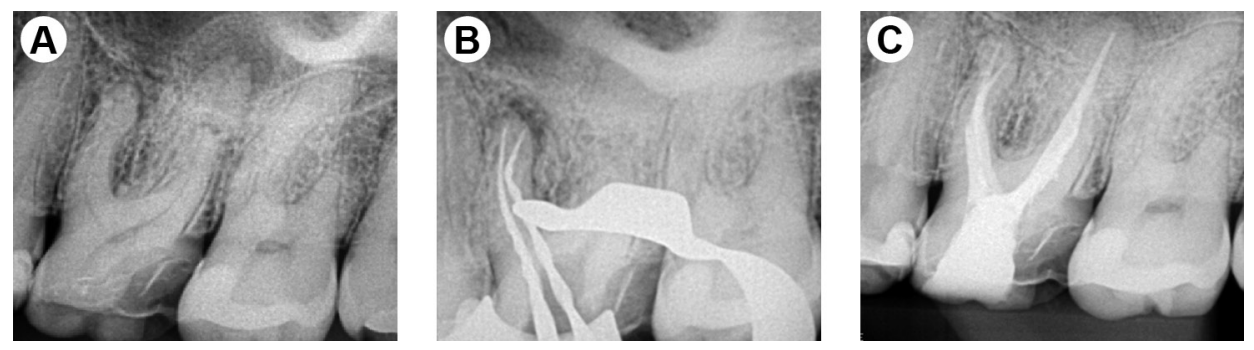

Figure 2. Case 2. A: Preoperative radiograph showing visible canal. After a size 30 hand instrument passively reached the WL, without filing action, an R50 file was indicated for the case; B: Transoperative radiograph showing two R50 files at WL in the MB and MB2 canal; and C: Final radiograph. 
where the radiograph showed the canal clearly from the pulp chamber to the apex, three possible situations where met: if a size 30 hand instrument passively reached, without filing action, the WL, the canal was considered large (Fig. $2 \mathrm{~A})$, and Reciproc 50 was selected for canal preparation. If a size 20 hand instrument passively reached, without filing action, the WL, the canal was considered medium (Fig. 3A), and Reciproc 40 was selected for canal preparation. If a size 20 hand instrument did not reach the WL passively, Reciproc 25 was selected.

After irrigating the root canal with $1 \mathrm{~mL}$ of $5.25 \% \mathrm{NaOCl}$, the selected Reciproc instrument was advanced in the canal space until reaching 2/3 of the previously estimated WL, moved in a slow and gentle in-and-out pecking motion with a $3 \mathrm{~mm}$ amplitude limit. After three complete pecking movements, the instrument was removed from the canal and its flutes were cleaned by insertion into a spoon-box. At this point, the root canal was irrigated with $1 \mathrm{~mL}$ of $5.25 \% \mathrm{NaOCl}$ for $1 \mathrm{~min}$. An ISO 10 hand file without being pre-curved was gently inserted into the canal, following the manufacturer's recommendations, with the purpose of determining the FWL using an electronic apex locator. No instrumentation movement was performed with the hand $\vec{s}$ file up to this point. In cases where the non-pre-curved ISO 10 hand file reached the FWL, root canal preparation with the Reciproc instrument was then completed attempting to reach the FWL. In the cases where the ISO 10 hand file did not reach the FWL, Reciproc instrumentation was also attempted till a perceived resistance in file advance, if so, was observed. All cases in which the Reciproc instrument was able to reach the full electronically determined $W L$, were classified as "Reaching the full WL" (RFWL) (Figs. 1B, $2 \mathrm{~B}$ and $3 \mathrm{~B}$ ). When some considerable resistance was found and the Reciproc instrument could not continue its natural advance toward the apex, the reciprocating preparation was stopped and the root canal was classified as "Not Reaching the full WL" (NRFWL) (Figs. 4A and 4B), and the canal preparation was concluded with hand files.

\section{Data Recording and Statistics}

The number of root canals classified as RFWL and NRFWL was recorded and tabulated in an Excel data sheet. Each instrument was used on a single tooth and then discarded. Instrument separation was also recorded. At the end of the canal preparation, matching Reciproc gutta-percha cones (VDW, Munich, Germany) were used as a master cone when the canal preparation was completed with a Reciproc instrument to the WL. If increased apical enlargement was done with hand files, a standardized gutta-percha cone was fitted as a master cone. All cones were disinfected in the $5.25 \% \mathrm{NaOCl}$ solution for 1 min prior to the obturation. Single cone was selected as obturation technique, and AH Plus (Dentsply, Konstanz, Germany) used as sealer. The gutta-percha was severed at the canal orifice with an electric heat carrier; a cold plugger was used to compact the softened gutta-percha in the coronal third of the root.
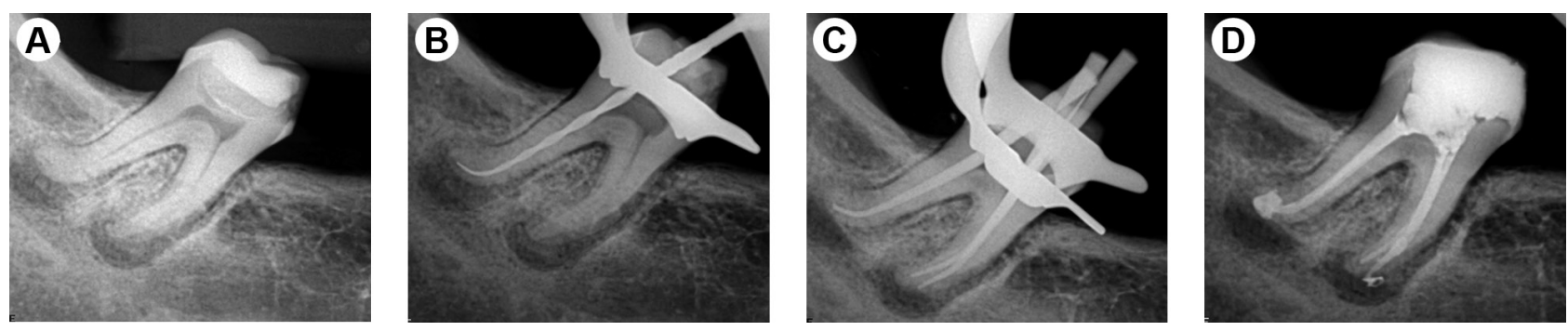

Figure 3. Case 3. A: Preoperative radiograph showing visible canal. The size 30 hand instrument was not able to reach the WL, then a size 20 hand instrument was used and it passively reached the WL, without filing action. Thus, a R40 file was indicated for the case; B: Transoperative radiograph showing the R40 file at WL in the distal canal; C: Gutta-percha cones adapted to the WL; and D: Final radiograph.
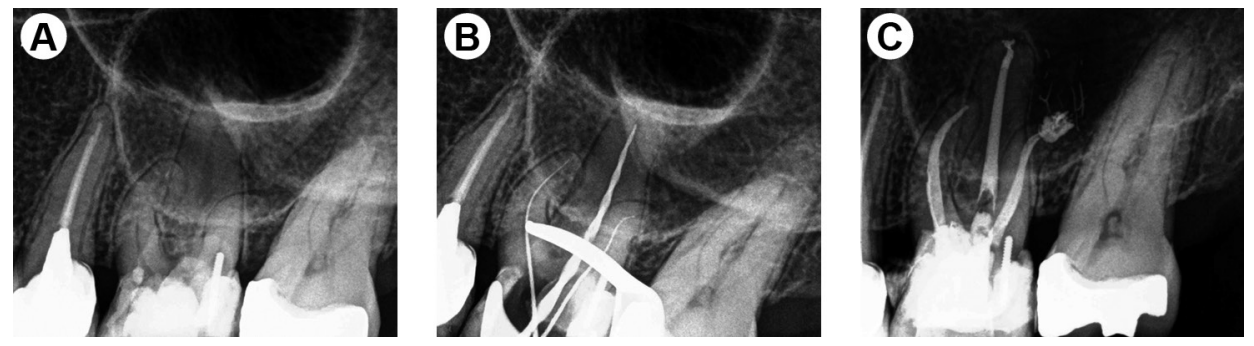

Figure 4. Case 4. A: Preoperative radiograph showing visible and curved canal; B: After failure to reach WL with Reciproc file, the canal preparation was finished with hand files. C: After root canal filling. 
After this, final post-operative radiograph was taken (Figs. 1D, 2C and 3D) and patients were carefully oriented to restore the tooth after the root canal treatment.

The frequency distributions (\%) of root canals classified as RFWL and NRFWL were compared both to overall treated canals and for each canal classification (narrow, medium and large) using a Pearson's squared-chi $\left(\chi^{2}\right)$ test. The $\alpha$-type error was set at 0.05 .

\section{Results}

The overall result showed that from a total pool of 673 root canals, the Reciproc instrument (R25, R40 or R50) reached the full WL in $96.28 \%$ of cases and only 3 fractures occurred. For canals classified as narrow, the percentage of RFWL was $95.37 \%$ with 3 fractures. As for the medium and large canals, the R40 or R50 instruments reached the full WL in $98.51 \%$ and $97.62 \%$ of cases respectively, with no fracture. Table 1 summarizes the overall results.

Squared-chi tests showed that the observed frequencies of RFWL and NRFWL canals were significantly different from the expected frequencies both to overall treated canals $\left(p=0.000, \chi^{2}=584.89\right)$ and for canal classifications $\left(p=0.000, \chi^{2}=381.87\right.$ for narrow canals; $p=0.000, \chi^{2}=127.12$ for medium canals and $p=0.000$, $\chi^{2}=76.19$ for large canals ).

Table 1. Frequency distributions (\%) of cases classified as reaching the full WL (RFWL) and not reaching the full WL (NRFWL) and fractured for each type of root canal

\begin{tabular}{lcccc}
\hline $\begin{array}{l}\text { Canal / } \\
\text { Instrument }\end{array}$ & $\mathrm{n}$ & RFWL & NRFWL & Fracture \\
\hline Narrow / R25 & 454 & $433(95.37 \%)$ & $18(3.96 \%)$ & $3(0.66 \%)$ \\
Medium / R40 & 135 & $133(98.51 \%)$ & $2(1.48) \%$ & 0 \\
Large / R50 & 84 & $82(97.62 \%)$ & $2(2.38) \%$ & 0 \\
Total & 673 & $648(96.28 \%)$ & $22(3.27 \%)$ & $3(0.44 \%)$ \\
\hline
\end{tabular}

\section{Discussion}

This clinical study reports a high frequency of Reciproc instruments reaching the full WL without a glide path, more than 95\% for overall root canals. Therefore, the tested null hypothesis was clearly rejected. The current result is in line with a recent in vitro study, which showed that Reciproc R25 instrument was able to reach the FWL without glide path in a high frequency of cases (7). To the best of the authors' knowledge, the current report is the first attempt to evaluate the clinical possibility of preparing the root canals with a reciprocating movement without the creation of a conventional glide path.

Beyond doubt the glide path is a technically demanding maneuver, but it is also a mandatory trans-operative step necessary in order to avoid NiTi instrument fracture by torsional failure $(11,12)$. This procedure was previously defined as a smooth radicular tunnel from the root canal orifice to its physiological terminus with the clear role of confirming that there is a free pathway for the rotary NiTi instrument (17). The effectiveness of the glide path procedure is related to its ability in avoiding the taperlock phenomenon, which stands for the binding of the instrument tip inside the root canal while its remaining bulk keeps turning. Taper-lock phenomenon stress usually occurs because the canal cross-section is smaller than the instrument tip $(18,19)$. Without a glide path, the area of contact between the cutting edges of NiTi instruments and the dentinal walls may increase considerably $(18,19)$ and so, torsional stress over rotary files may be dramatically increased $(12,18)$. These arguments explain why the lack of a previous glide path procedure results in a significant increase in NiTi file separation following rotary preparation (12). In the present study, out of 673 instrumented root canals, only 3 fractures $(0.44 \%)$ occurred in root canals with small radius of curvature (Figs. 5A, 5B and 5C). This very low fracture rate is an important result from a technical standpoint, as the overall rate of NiTi instrument
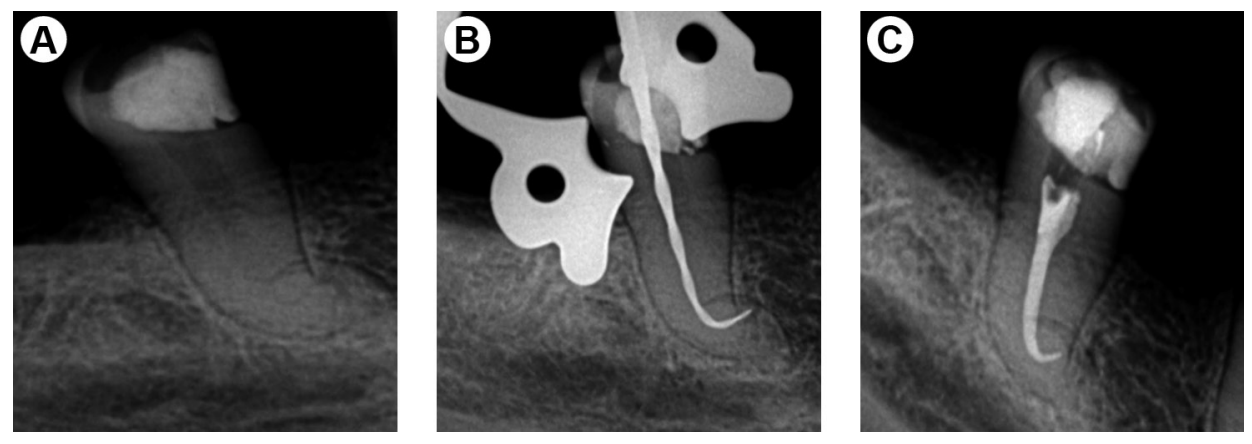

Figure 5. Case 5. A: Preoperative radiograph showing a partially invisible and curved canal. R25 file was indicated for this case; B: Transoperative radiograph showing the R25 file at WL. At this moment a fracture was observed in the apical third of root canal; C: Final radiograph. Even after all efforts, the file was not removed and the root canal was filled with the file remaining in the apical third. 
separation in rotary movement has been reported to be markedly higher; $1.83 \%$ (20), 5\% (21) and 16\% (22) even following glide path. Therefore, reciprocating movement may play a role in preventing instrument separation even without a glide path, as the cyclical reversal of rotation seems to drastically reduce the torsional stress over the NiTi instrument. Extended cyclic fatigue life of reciprocating systems when compared to rotary systems has also been extensively observed $(2,5,6,8,10)$.

It can be claimed that a "guide path" may have been created after the passive use of a \#10 K file after coronal flaring with Reciproc instrument in this study. However, as reported above and previously, a true glide path implies that the root canal cross-section should be bigger than the tip of the first used NiTi rotary instrument $(11-13,23)$. Thus, an enlargement of the root canal should be provided to a size \#15 or \#20, in order to consider a smooth glide path for mechanical instrumentation to be created. For the case of medium and large canals, where size 20 and 30 hand instruments were used to select the Reciproc instrument, no manual root canal filing action has been performed. In these cases, in which the root canals were radiographically visible to the entire length, it may be glide path already existed. Berutti et al (11) recommended that the root canal diameter should be at least one size 4. larger than the tip of the first rotary instrument to be used in that root canal (11). Therefore, ideally, the root canal should be widened to provide the minimal enlargement and the smooth pathway required to prevent fracture by torsional stresses.

The high frequency of Reciproc instruments reaching the apex without a conventional glide path, as demonstrated in this clinical report, may be understood as the result of the interplay of three main factors: (i) the reciprocation kinematics, (ii) the instrument cross-section and (iii) the M-wire alloy. The advantages of the reciprocation kinematics are somehow based on the balanced force concept. This technique has shown its clinical relevance in reaching the full electronically determined WL in severely curved canals prepared with hand files (24). Thus, reciprocation can be considered as a mechanically driven balanced force, which might be related to the efficacy of the instrument in advancing toward the apex (6), reducing the taper lock due to small angles of instrument cycles plus the improved cyclic fatigue resistance $(2,5,6,8,10)$. Of note, the reciprocating movement per se was able to improve the cyclic fatigue resistance of several NiTi instruments when compared to rotary motion (8), which corroborates the observation of an extended cyclic fatigue life of the F2 ProTaper instrument used in reciprocating movement
(2). Furthermore, the reduced cross-sectional metal mass plus the use of the superelastic M-wire alloy provide great flexibility and cutting ability specifically to the Reciproc instrument, which also may help understanding the current results.

Some concern regarding the use of an engine driven NiTi file without a glide path is based on a perceived reduction in the occurrence of canal modifications and anomalies when previous glide path is performed using rotary motion (1113). A recent study showed that canal modifications seem to be significantly reduced when glide path is performed previously to the WaveOne NiTi reciprocation single-file system (25). However, there are no data on the influence of glide path on geometric canal modifications with Reciproc files. Both reciprocating systems are made of the same NiTi allow (M-wire), but they have quite different cross sections, taper and flexibility. Reciproc instruments have an S-shaped cross-section with two cutting blades while WaveOne instruments have an increased bulk with a modified convex triangular cross-section in the tip and a convex triangular cross-section in the middle and coronal portion. It has been reported that the larger the cross-sectional area, the higher the flexural and torsional stiffness (26). In this way, file design (e.g. cross-sectional shape, diameters of core, etc.) could have a significant influence on the necessity of glide path to prevent instrumentation errors. It becomes apparently clear from the current study that the use of Reciproc files could not be related with such errors, since none was clinically observed in the present study, and as earlier described, only 3 instrument fractures occurred.

When attempting to study the frequency of a given event in a population, a control group is not necessarily required, as in the case of the present study, where a squared-chi statistical procedure is enough to certify the significance of the observed frequency. Thus, a glide path control group was not included since the main purpose of the present study was limited to observe the frequency of RFWL canals, when the selection of the Reciproc instruments is based on an adequate preoperative radiograph, according to the manufacturer's recommendation. There is no doubt that the Reciproc instrument was able to reach the FWL of teeth in a high frequency of cases. Furthermore, within the limits of the type of the sampling in the present study, it is reasonable to conclude that performing the glide path procedure would certainly not imply in less RFWL canals by the Reciproc instruments.

In summary, it was observed that enlarging the root canals using Reciproc instruments up to the FWL without a glide path could be attained in a high frequency in primary treatments performed by specialists. This result suggests the possibility of using only one instrument in reciprocating motion to enlarge the root canal space of 
teeth by a simpler and safe approach without demanding a glide path procedure.

\section{Resumo}

0 objetivo do presente estudo foi avaliar prospectivamente a frequência de dentes em que os instrumentos Reciproc foram capazes de alcançar o comprimento de trabalho (CT) completo. Este estudo com série de casos envolveu 277 dentes consecutivos que necessitavam de tratamento endodôntico primário realizado com o sistema Reciproc (VDW) sem a realização de uma via de penetração inicial (glide path) prévio por 3 endodontistas experientes. Instrumentos R25, R40 ou R50 foram selecionados, respectivamente, para canais estreitos, médios e largos, de acordo com as radiografias pré-operatórias, seguindo a recomendação do fabricante. Os canais foram instrumentados e classificados como atingindo o WL completo (ACTC) e de não atingindo o WL completo (NACTC), de acordo com a capacidade do instrumento Reciproc de alcançar o CT completo determinado eletronicamente, sem a realização de glide path. Finalmente, os canais foram preenchidos usando a técnica de obturação de cone único. 0 teste de qui-quadrado de Pearson comparou a frequência das distribuições de canais classificados como ACTC e NACTC. A partir de um pool total de 673 canais radiculares, instrumentos Reciproc atingiram o CTC em $96,28 \%$ dos casos e 3 fraturas ocorreram. Para canais estreitos, a percentagem de ACTC foi 95,37\% com 3 fraturas. Para canais médios e largos, os instrumentos R40 e R50 atingiram o CTC em 98,51\% e 97,62\% dos casos, respectivamente, sem fratura. Ampliação dos canais radiculares utilizando os instrumentos Reciproc até o CTC sem a realização de glide path foi bem sucedida em uma grande porcentagem dos casos. Esta série de casos sugere a possibilidade de utilizar um único instrumento para ampliar o espaço do canal radicular usando uma abordagem mais simples, sem um procedimento prévio de glide path.

\section{References}

1. Ruddle CJ. Canal preparation: single-file shaping technique. Dent Today 2012;31:126-129.

2. De-Deus $G$, Moreira $E$, Lopes $H$, Elias $C$. Extended cyclic fatigue life of F2 ProTaper instruments used in reciprocating movement. Int Endod J 2010;43:1063-1068.

3. Paqué $F$, Zehnder $M$, De-Deus G. Microtomography-based comparison of reciprocating single-file F2 ProTaper technique versus rotary full sequence. J Endod 2011;37:1394-1397.

4. Alves FR, Rôças IN, Almeida BM, Neves MA, Zoffoli J, Siqueira JF Jr. Quantitative molecular and culture analyses of bacterial elimination in oval-shaped root canals by a single-file instrumentation technique. Int Endod J 2012;45:871-877.

5. Castelló-Escrivá R, Alegre-Domingo T, Faus-Matoses V, Román-Richon S, Faus-Llácer VJ. In vitro comparison of cyclic fatigue resistance of ProTaper, WaveOne, and twisted files. J Endod 2012;38:1521-1524.

6. Gavini G, Caldeira C, Akisue $E_{1}$ Candeiro G, Kawakami D. Resistance to flexural fatigue of Reciproc R25 files under continuous rotation and reciprocating movement. J Endod 2012;38:684-687.

7. De-Deus G, Arruda TE, Souza EM, Neves A, Magalhães K, Thuanne E, et al.. The ability of the Reciproc R25 instrument to reach the full root canal working length without a glide path. Int Endod J 2013;46:993998.

8. Kiefner P, Ban M, De-Deus G. Is the reciprocating movement per se able to improve the cyclic fatigue resistance of instruments? Int Endod J doi: 10.1111/iej.12166. [Epub ahead of print]
9. Koçak S, Koçak MM, Sağlam BC, Türker SA, Sağsen B, Er O. Apical extrusion of debris using self-adjusting file, reciprocating single-file, and 2 rotary instrumentation systems. J Endod 2013;39:1278-1280.

10. Lopes HP, Elias CN, Vieira MV, Siqueira JF Jr, Mangelli M, Lopes WS, et al.. Fatigue life of Reciproc and Mtwo instruments subjected to static and dynamic tests. J Endod 2013;39:693-696.

11. Berutti $E$, Negro $A$, Lendini $M$, Paqualini D. Influence of manual preflaring and torque on the failure rate of ProTaper rotary instruments. J Endod 2004;304:228-230.

12. Patiño PV, Biedma B, Liébana $C$, Cantatore G, Bahillo J. The influence of a manual glide path on the separation rate of NiTi rotary instruments. J Endod 2005;31:114-116.

13. Berutti, E. Negro A, Lendini M. Use of nickel-titanium rotary PathFile to create the glide path: comparison with manual preflaringin simulated root canals. J Endod 2009;35:408-412.

14. Megouez C, Rilliard F, Matossian L, Nassiri K, Mandel E. Influence of operator experience on canal preparation time when using the rotary Ni-Ti ProFile system in simulated curved canals. Int Endod J 2003;36:161-165.

15. Al-Omari MA, Aurich T, Wirtti S. Shaping canals with ProFile and K3 instruments: does operator experience matter? Oral Surg Oral Med Oral Pathol Oral Radiol Endod 2010;110:e50-e55.

16. Yared G. Reciproc literature [WWW document]. url: http:// endodonticcourses.com/literature [accessed on 2 January 2016]

17. West J. The endodontic glide path: "secret to rotary safety". Dent Today 2010;29:86-93.

18. Peters 0, Peters I, Schonenberger K, Barbakow F. ProTaper rotary root canal preparation: assessment of torque and force in relation to canal anatomy. Int Endod J 2003;36:93-99.

19. Blum J, Machtou P, Micallef J. Location of contact areas on rotary Profile instruments in relationship to the forces developed during mechanical preparation on extracted teeth. Int Endod J 1999;32:108114.

20. Tzanetakis GN, Kontakiotis EG, Maurikou DV, Marzelou MP. Prevalence and management of instrument fracture in the postgraduate endodontic program at the Dental School of Athens: A five-year retrospective clinical study. J Endod 2008;34:675-678.

21. Parashos $\mathrm{P}$, Gordon I, Messer HH. Factors influencing defects of rotary nickel-titanium endodontic instruments after clinical use. J Endod 2004:30:722-725.

22. Inan U, Gonulol N. Deformation and fracture of Mtwo rotary nickeltitanium instruments after clinical use. J Endod 2009;35:1396-1399.

23. Elnaghy AM, Elsaka SE. Evaluation of root canal transportation, centering ratio, and remaining dentin thickness associated with ProTaper Next instruments with and without glide path. J Endod 2014;40:2053-2056.

24. Southard DW, Oswald RJ, Natkin E. Instrumentation of curved molar root canals with the Roane technique. J Endod 1987;13:479-489.

25. Berutti E, Paolino DS, Chiandussi G, Alovisi M, Cantatore G, Castellucci A, et al.. Root canal anatomy preservation of WaveOne reciprocating files with or without glide path. J Endod 2012;38:101-104.

26. Zhang EW, Cheung GS, Zheng YF. Influence of cross-sectional design and dimension on mechanical behavior of nickel-titanium instruments under torsion and bending: a numerical analysis. J Endod 2010;36:1394-1398. 